\title{
Product Innovation Incentives: Monopoly vs. Competition
}

\author{
Yongmin Chen and Marius Schwartz *
}

January 29,2010

\begin{abstract}
Unlike Arrow's result for process innovations, the gain from a product innovation can be larger to a secure monopolist than to a rivalrous firm that would face competition from independent sellers of the old product. A monopolist incurs profit diversion from its old good but may gain more than a rivalrous firm on the new good by coordinating the prices. In a Hotelling framework, we find simple conditions for the monopolist's gain to be larger. We explain why the ranking of incentives differs under vertical product differentiation and suggest a principle that may determine the ranking for additional demand systems.
\end{abstract}

${ }^{*}$ Chen: Department of Economics, University of Colorado, Boulder, CO $80309<$ yongmin.chen@colorado.edu>. Schwartz: Department of Economics, Georgetown University, Washington DC $20057<$ mariusschwartz@mac.com>. We thank Axel Anderson, Andrew Daughety, Ian Gale, Richard Gilbert, Ed Green, David Malueg, Federico Mini, David Sappington, Daniel Vincent, and Ralph Winter for helpful discussions and comments. 


\section{Introduction}

Does initial market power dilute a firm's incentive to invest in obtaining patentable innovations because of a desire to protect existing profit? In a seminal paper Arrow (1962) analyzed process innovations that lower the cost of an existing product. He showed that a secure monopolist has a weaker incentive to obtain a process innovation than would a competitive firm facing the same market demand. In the same environment we study product innovations. Our main contribution is to show that Arrow's ranking can be reversed - the incentive for product innovation can be stronger under secure monopoly. ${ }^{1}$ Compared to an entrant, a monopolist adding a new product will divert profit from its old product but may gain more on the new product by coordinating the prices of both products. (These diversion and coordination effects are conceptually similar, but not identical, to the literature's "replacement" and "efficiency" effects.)

We analyze nondrastic product innovations: the new good $B$ is a differentiated substitute for the initial good $A$ and does not entirely displace it. We compare a firm's incentive to add product $B$ under three alternative regimes, with the firm's gain denoted in parentheses: secure Monopoly $\left(G^{m}\right)$ - a monopolist controls product $A$ and only that same firm can add $B$; ex post Duopoly $\left(G^{d}\right)$ - a monopolist controls product $A$ but only a different firm can add $B$; and Competition $\left(G^{c}\right)$ - product $A$ is supplied by homogeneous Bertrand rivals (Arrow's case), and any firm can add $B$. One motivation for these comparisons is that policy interventions can alter the market structure and, hence, the innovation incentive, as under the following scenarios.

Regulation Scenario: compare $G^{m}$ with $G^{d}$. Suppose there is a durable franchise monopolist in $A$ and the policy choice is between (i) granting that firm also the monopoly rights over a competing future product $B$, versus (ii) barring that firm from $B$. Under regime (i), the incumbent is unconcerned with preemption in $B$, so its gain from adding $B$ is given by $G^{m}$; under regime (ii), only an entrant can innovate in $B$, and its gain is given by its profit under ex post duopoly, $G^{d}$. Option (ii) may be motivated by a (correct) concern that the incumbent would price the new product higher than would an entrant.

Merger Scenario: compare $G^{m}$ with $G^{c}$. Suppose that producers of good $A$ are initially competitive, only they have the requisite assets to add product $B$, and they propose a mergerto-monopoly in $A$. The gain from adding $B$ is $G^{m}$ if the merger is approved and $G^{c}$ if the merger is rejected.

\footnotetext{
${ }^{1}$ Observe that, like Arrow, we compare incentives under secure monopoly and under alternative market structures, not the incentives of a threatened monopolist to those of an entrant into the same market. It is well known from the preemption literature (discussed in Section 2) that a threatened monopolist can have the greater incentive to innovate. Policy motivations for taking secure rather than threatened monopoly as the relevant benchmark are discussed shortly.
} 
Patent Scenario: compare $G^{m}$ with $G^{c}$. Good $A$ is supplied by a monopolist protected by a patent, that also blocks innovation in $B$. If the patent is retained, the innovation incentive is $G^{m}$; if it is voided, market $A$ becomes competitive, and the innovation incentive changes to $G^{c}$.

Typically, $G^{c}<G^{d}$ : the innovator's profit will be smaller if the substitute good $A$ is supplied competitively rather than by one firm, since $A$ 's price will be lower under competition. Our interest is in comparing the incentives under these alternative market structures with the incentive under monopoly. We represent product differentiation as horizontal, following the classic framework of Hotelling (1929; see also Tirole 1988) but adapted to allow asymmetries: the products can differ in qualities - their value to consumers before transport costs - or, equivalently, in their unit costs. We show that $G^{m}>G^{d}$ if and only if the new product has higher quality than the old, and that $G^{m}>G^{c}$ always holds. Thus, the incentive for product innovation can be larger under secure monopoly than under market structures that admit product market rivalry, in contrast to Arrow's finding for process innovations.

To our knowledge, the only authors who have explored product innovation in a similar setting are Greenstein and Ramey (1998) and Gilbert (2006, Appendix). Gilbert shows that Arrow's scale effect favoring a Bertrand competitor's incentive to innovate relative to a monopolist's can be reversed if the initial competition is in differentiated rather than homogeneous products. In Gilbert's example the innovator discards the old product, which is dominated by the new one, akin to a process innovation. ${ }^{2}$ Our interest is in cases where the products are imperfect substitutes and a monopolist would sell both. The paper closest to ours is Greenstein and Ramey (1998). They compare the same regimes (except that under duopoly they assume Cournot rather than Bertrand competition), but they represent product differentiation as vertical (Shaked and Sutton 1983, Tirole 1988). Importantly, the ranking of incentives differs. They find $G^{m}=G^{c}<G^{d}{ }^{3}$ whereas we find $G^{m}>G^{c}$, and even $G^{m}>G^{d}$ is possible.

The remainder of the paper is organized as follows. To place our contribution in context,

\footnotetext{
${ }^{2}$ Consumers are located on a Hotelling line, have unit demands, and the market is covered under monopoly or competition, so normalize the constant total sales to 1 . All consumers place an equal premium $\mathrm{P}$ on the new product over the old (so the innovation is like a cost reduction). If a monopolist located at 0 innovates, it raises price by $\mathrm{P}$ to the whole market so its gain is $\mathrm{P}$. Now suppose that the innovating firm located at 0 competes with a rival at the other end. If the products were homogeneous (zero transport costs), the innovator would capture the market with a trivial price cut and its gain would be $\mathrm{P}$, as under monopoly; with differentiation, its gain is lower because to capture the market would require an increase in margin smaller than $\mathrm{P}$.

${ }^{3}$ The equality is shown in their Proposition 2(a), and the inequality in their Proposition 4(a). Commenting on Proposition 2(a), they note that "by appropriately perturbing the utility functions ... either competition or protected monopoly may provide strictly greater returns; thus equality should be interpreted to mean that returns will be very close over a large range of demand conditions ..." Moreover, since duopoly yields strictly higher innovation returns than competition and, therefore, than monopoly, a fair reading of their results is that innovation incentives are weakly lower under protected monopoly than under product market rivalry.
} 
Section 2 starts with a brief synthesis of factors that affect innovation incentives under different market structures, distinguishing drastic from nondrastic innovation and our secure monopolist case from a monopolist threatened by entry. ${ }^{4}$ Section 3 presents our basic model. Section 4 establishes our main result. In an asymmetric Hotelling framework, the incentive to add a new product can be greatest under monopoly. In some such cases, overall welfare also is higher under monopoly than under more competitive market structures. Of course, this observation should not be construed as advocating monopoly, because monopoly has other well-known deficiencies; it merely cautions against sweeping claims that product market monopoly invariably retards innovation. Section 5 explains why our ranking of incentives under horizontal differentiation differs from Greenstein and Ramey's (1998) under vertical differentiation. The different preference patterns of the marginal consumers in the two settings enable a two-product monopolist to raise the price of its old product and divert sales to the new without leaking sales to outside goods under horizontal differentiation but not under vertical. Thus, horizontal differentiation magnifies the price coordination advantage to a monopolist innovator that also controls the old product. Section 6 presents brief conclusions.

\section{Innovation Incentives and Market Structure: a Brief Synthesis}

Consider a process or product innovation that yields its owner a permanent monopoly over the new technology. Our benchmark market structure is a secure monopoly: only the incumbent firm may deploy the new technology; if it does not, the status quo persists. Denote the monopolist's profit stream without the innovation by $\pi_{0}^{m}$ and with it by $\pi_{1}^{m}\left(\pi_{1}^{m}\right.$ includes any profit from the old technology, which can remain valuable in the case of a product innovation). The monopolist's gain from the innovation, before acquisition costs, is $G^{m}=\pi_{1}^{m}-\pi_{0}^{m}$. (This would also be the incentive of a monopolist threatened by entry but acting myopically.) Next, consider two alternative market structures where the innovating firm initially earns zero profit: it is either one of several homogeneous Bertrand competitors with the old technology (Arrow's scenario), or an entrant facing an incumbent monopolist with the old technology. Post innovation, the firm may face rivalry from the old technology ("may" because the old technology could become not viable), so denote its profit by $\pi_{1}^{r}$, and its incentive to innovate by $G^{r}=\pi_{1}^{r}-0$. The difference in incentives of a secure monopolist and a rivalrous firm can be decomposed as $G^{m}-G^{r}=\left(\pi_{1}^{m}-\pi_{1}^{r}\right)-\left(\pi_{0}^{m}-0\right)$, the difference in profits with the innovation minus the difference without it.

The term $\left(\pi_{0}^{m}-0\right)$ has been called the "replacement effect" (Tirole 1988): deploying a substitute new technology will reduce profit from the old, and since a monopolist has higher initial

${ }^{4}$ For broader reviews see Gilbert (2006), Reinganum (1989), or Tirole (1988). 
profit it has more to lose from innovating. ${ }^{5}$ This tells the whole story if the innovation is so major that the old technology no longer affects the innovator's profit - a drastic innovation. A monopolist then has the smaller incentive since post innovation profit will be the same regardless of the initial market structure, $\pi_{1}^{m}=\pi_{1}^{r}{ }^{6}$

With a nondrastic innovation, however, $\pi_{1}^{m}>\pi_{1}^{r}$ : an innovator earns higher profit when it controls also the old technology than when it faces viable competition from that technology. The difference in incentives, $G^{m}-G^{r}=\left(\pi_{1}^{m}-\pi_{1}^{r}\right)-\left(\pi_{0}^{m}-0\right)$, now reflects two opposing effects: a secure monopolist earns more without the innovation than does a differently situated firm, but also earns more with the innovation. ${ }^{7}$ Despite this seeming ambiguity, Arrow was able to rank the incentives for process innovations, but his argument cannot be applied to product innovations. We revisit this key issue after contrasting the incentives of a secure and a threatened monopolist.

If a threatened monopolist fails to innovate, entry will occur deterministically or stochastically. Gilbert and Newbery (1982), building on the preemptive investment literature (e.g., Eaton and Lipsey 1979), show that an incumbent monopolist who can acquire the innovation will indeed outbid an entrant if the innovation's arrival date is known. The argument holds for a process or product innovation and runs as follows. An entrant will acquire the innovation at date $T$ unless the incumbent has preempted. If the incumbent preempts, it controls both technologies and earns the new monopoly profit $\pi_{1}^{m}$. Instead, if entry occurs there will be asymmetric duopoly in which the entrant uses the new technology and earns $\pi_{1}^{d}$ (the analogue of $\pi_{1}^{r}$ ), and the incumbent uses the old technology and earns $\pi_{0}^{d}$ instead of the old monopoly profit $\pi_{0}^{m}$. The incumbent's gain from preempting just before $T$ is $G^{m p}=\pi_{1}^{m}-\pi_{0}^{d}=\left(\pi_{1}^{m}-\pi_{0}^{m}\right)+\left(\pi_{0}^{m}-\pi_{0}^{d}\right)$. This exceeds $G^{m}$, the gain to a secure monopolist, by $\left(\pi_{0}^{m}-\pi_{0}^{d}\right)$, because acquiring the innovation now has the added benefit of foiling entry and preventing a drop in profit. ${ }^{8}$

\footnotetext{
${ }^{5}$ The new technology replaces (and augments) the entire profit from the old in the case of a process innovation, since the innovator will abandon the old technology. For a product innovation, the new good may divert ("replace") only some of the profit from the old, as discussed in Section 2.

${ }^{6}$ In Arrow's analysis, a process innovation is drastic if the new monopoly price is below the old marginal cost: the innovator then prices as an unconstrained lower-cost monopolist whatever the pre-innovation structure. Whether a product innovation is drastic, however, can depend on the initial market structure. For the ex post difference $\pi_{1}^{m}-\pi_{1}^{r}$ to be zero, the innovation must be drastic under each of the alternative structures (see Section 3).

${ }^{7}$ The analysis is unchanged when comparing a secure monopolist and an innovating firm that initially is imperfectly competitive and earns positive (rather than zero) profit $\pi_{0}^{r}$, provided none of its rivals can deploy the new technology. (In the expression $G^{m}-G^{r}, \pi_{0}^{r}$ replaces 0, but the rankings still would be $\pi_{1}^{m}>\pi_{1}^{r}$ and $\pi_{0}^{m}>\pi_{0}^{r}$.) If other firms also can innovate, then preexisting profit creates an added motive for acquiring the innovation - to deny it to a competitor. Such preemption considerations will be discussed shortly.

${ }^{8}$ Recall that we assumed secure property rights for the innovator. Katz and Shapiro (1987) show that if imitation is possible, a firm may benefit if a rival innovates and a threatened monopolist could have a weaker incentive to innovate than a secure monopolist. In his broad survey, Gilbert (2006) emphasizes that stronger product-market competition can have opposite effects on innovation incentives when innovation property rights (legal or de facto)
} 
Comparing a preempting monopolist's incentive and an entrant's yields $\left(\pi_{1}^{m}-\pi_{0}^{d}\right)-\pi_{1}^{d}=\pi_{1}^{m}-$ $\left(\pi_{0}^{d}+\pi_{1}^{d}\right)$, industry profit when a single firm has a monopoly over both technologies minus industry profit under asymmetric duopoly. ${ }^{9}$ Assuming no diseconomies of scale or scope, for a nondrastic innovation $\pi_{1}^{m}>\left(\pi_{0}^{d}+\pi_{1}^{d}\right)$, reflecting the monopolist's ability to coordinate industry output or pricing. ${ }^{10}$ Tirole (1988) calls this post-innovation difference the "efficiency effect", where efficiency refers only to producer welfare. Thus, Gilbert and Newbery's analysis implies that a threatened monopolist will outbid an entrant for a nondrastic innovation when the innovation process is deterministic. ${ }^{11,12}$

Our paper considers a secure rather than threatened monopolist. The "efficiency effect" stressed in the preemption literature actually has a counterpart for a secure monopolist: with the innovation it earns larger profit than would a firm that faced product-market rivalry, $\pi_{1}^{m}>$ $\pi_{1}^{r} .{ }^{13}$ This condition holds in Arrow's setting for a nondrastic process innovation: the new

are weak rather than strong. If weak, an innovator's return may come mainly from deploying the innovation itself instead of licensing, so its gain may be larger when competition is weak (a possible basis for Schumpeter's view that monopoly power can encourage innovation).

${ }^{9}$ Salant (1984) observes that if exclusive licensing for a lump sum fee is feasible, the product market will remain
a monopoly regardless of who innovates, though he recognizes that antitrust constraints could prevent this. Gilbert
and Newbery (1984) note that transaction costs also could impede licensing. Gans and Stern (2000) adopt Salant's
framework (and show how imitation ability and entry costs affect bargaining over the license fee and, hence,
innovation incentives). In contrast, Gallini and Winter (1985) and Katz and Shapiro (1987) allow licensing (which
lowers industry costs) but not exclusive licensing to create monopoly, e.g., due to legal prohibitions (Gallini and
Winter, p. 242). We will assume that if the innovator is a firm other than an initial monopolist, it will face
competition from the old product. In our model, licensing delivers no efficiencies (the same new product is added
in all cases); and our comparison between secure monopoly and rivalrous market structures is motivated partly by
policy concerns with preserving price competition, concerns that naturally limit licensing-for-monopolization.

${ }^{10}$ Intuitively, if the incumbent mimicked the equilibrium that would prevail under duopoly, it would earn $\pi_{0}^{d}+\pi_{1}^{d}$, but it can generally do better by coordinating the choices of the two units. On the strategic limits of this mimicking argument for the persistence of monopoly see Lewis (1983), Judd (1985), and Malueg and Schwartz (1991). Spulber (2009) considers a different departure from the mimicking principle by assuming that a firm cannot supply both products. An innovator can either license its technology to the incumbent or use it to produce a differentiated product. When the product is sufficiently differentiated from the incumbent's, industry profit is higher with differentiated duopoly than with a single product monopoly, and there is entry in equilibrium.

${ }^{11}$ Reinganum $(1983,1989)$ shows that if the innovation's arrival date instead is a stochastic function of firms' R\&D spending, as in patent races, the monopolist is more willing than an entrant to reduce its R\&D and accept a delay, due to its status quo profit. This probabilistic replacement effect leads an incumbent monopolist to bid less than an entrant when the innovation is drastic or, by continuity, close enough to drastic. Heuristically, the monopolist's incentive to innovate can now be expressed as $\pi_{1}^{m}-\left[p \pi_{0}^{m}+(1-p) \pi_{0}^{d}\right]$ where $p$ is the probability that, conditional on the incumbent not innovating, the entrant also will fail to innovate. Gilbert and Newbery's analysis corresponds to $p=0$; secure monopoly corresponds to $p=1$.

\footnotetext{
${ }^{12}$ Chen (2000) extends Gilbert and Newbery's analysis by letting the entrant produce also the old product. He shows that the incentive to add the new product is greater for the incumbent than the entrant if the products are strategic complements and vice versa for strategic substitutes.

${ }^{13}$ When the innovator becomes an ex post duopolist, $\pi_{1}^{r}=\pi_{1}^{d}$ and our comparison reads $\pi_{1}^{m}>\pi_{1}^{d}$. The efficiency effect encountered in the preemption literature, $\pi_{1}^{m}>\pi_{1}^{d}+\pi_{0}^{d}$ is a stronger condition since the right-hand side
} 
monopoly price then exceeds the old marginal cost, so Bertrand competition would constrain the innovator's profit below $\pi_{1}^{m}$. However, the opposing replacement effect - absent under deterministic preemption - dilutes the incentive of a secure monopolist, leaving the difference $G^{m}-G^{r}=\left(\pi_{1}^{m}-\pi_{1}^{r}\right)-\left(\pi_{0}^{m}-0\right)$ seemingly ambiguous. Arrow nevertheless is able to prove that $G^{m}<G^{r}$ through a different argument: the value of a process innovation comes from reducing the firm's marginal cost and this cost reduction applies to a smaller output under monopoly (see also Tirole 1988). This argument, however, is specific to process innovations.

\section{The Model}

The market has an initial product, $A$. An innovation will bring a new product, $B$. The innovator obtains exclusive rights over $B$. The marginal cost of producing either $A$ or $B$ is constant, $c \geq 0$. The products are imperfect substitutes. Denote the demand functions by $q_{A}=D_{A}\left(p_{A}, p_{B}\right)$, $q_{B}=D_{B}\left(p_{A}, p_{B}\right)$, and assume that over the relevant ranges

$$
\frac{\partial q_{i}}{\partial p_{i}}<0 \text { and } \frac{\partial q_{i}}{\partial p_{j}}>0, \text { for } i=A, B \text { and } i \neq j
$$

When only $A$ is available, its demand is $q_{A}=D_{A}^{m}\left(p_{A}\right)$.

Let $p_{A}^{m}$ denote the price charged by a monopolist over product $A$ alone; $\left(p_{A}^{m m}, p_{B}^{m m}\right)$ denote the prices charged when a single firm is the monopolist over both products; and $\left(p_{A}^{d}, p_{B}^{d}\right)$ denote the prices charged under duopoly - only the incumbent firm supplies product $A$ and only a different innovator supplies $B$. Assume that $p_{A}^{m},\left(p_{A}^{m m}, p_{B}^{m m}\right)$, and $\left(p_{A}^{d}, p_{B}^{d}\right)$ exist and are unique.

The profits for product $A$ under a single-product monopoly, for $A$ and $B$ under a two-product monopoly, and for both products when they compete under duopoly are denoted as:

$$
\begin{aligned}
& \pi_{A}^{m}=\left(p_{A}^{m}-c\right) D_{A}^{m}\left(p_{A}^{m}\right) ; \\
& \pi_{A}^{m m}=\left(p_{A}^{m m}-c\right) D_{A}\left(p_{A}^{m m}, p_{B}^{m m}\right), \quad \pi_{B}^{m m}=\left(p_{B}^{m m}-c\right) D_{B}\left(p_{A}^{m m}, p_{B}^{m m}\right) ; \\
& \pi_{A}^{d}=\left(p_{A}^{d}-c\right) D_{A}\left(p_{A}^{d}, p_{B}^{d}\right), \quad \pi_{B}^{d}=\left(p_{B}^{d}-c\right) D_{B}\left(p_{A}^{d}, p_{B}^{d}\right) .
\end{aligned}
$$

Focusing on nondrastic product innovations, we assume $\pi_{A}^{m m}+\pi_{B}^{m m}>\pi_{A}^{d}+\pi_{B}^{d}$.

\section{Product $A$ Is Initially Monopolized}

includes also $\pi_{0}^{d}$, the incumbent's profit under duopoly. Both conditions are driven by a monopolist's superior ability to coordinate industry decisions. 
If the monopoly producer of $A$, firm 1 , innovates by adding product $B$, it becomes the twoproduct monopolist. Its gain from adding product $B$ is

$$
G^{m}=\pi_{A}^{m m}+\pi_{B}^{m m}-\pi_{A}^{m}
$$

If only an entrant, firm 2 , can add product $B$, then post innovation the market becomes a duopoly. The entrant's gain is

$$
G^{d}=\pi_{B}^{d}
$$

Comparing $G^{m}$ and $G^{d}$ is relevant, for example, for the Regulation Scenario discussed in the Introduction. ${ }^{14}$ The difference in incentives can be expressed as

$$
G^{m}-G^{d}=\left(\pi_{B}^{m m}-\pi_{B}^{d}\right)-\left(\pi_{A}^{m}-\pi_{A}^{m m}\right)
$$

Here, $\left(\pi_{A}^{m}-\pi_{A}^{m m}\right)>0$ is the diversion effect on product $A$ : only the initial monopolist internalizes the fact that its profit from good $A$ falls when it adds product $B$. The term $\left(\pi_{B}^{m m}-\pi_{B}^{d}\right)$ is the coordination effect on product $B$ : profit from the new product will generally differ between a two-product monopolist and an independent innovator, because only the monopolist can coordinate the prices of the two goods to maximize its overall profit.

Remark 1 (decomposition) The incentive to add product $B$ is greater for a monopolist over good $A$ than for an entrant that would compete in ex post duopoly if and only if the coordination effect on $B$ outweighs the diversion effect on $A: G^{m}>G^{d} \Longleftrightarrow\left(\pi_{B}^{m m}-\pi_{B}^{d}\right)>\left(\pi_{A}^{m}-\pi_{A}^{m m}\right)$.

Remark 2 The coordination effect on product $B$ can be negative, $\pi_{B}^{m m}<\pi_{B}^{d}$.

The inequality in Remark 2 can arise if the new product is significantly weaker than (but differentiated from) the old. Section 4 provides an example in the asymmetric Hotelling model. However, $\pi_{B}^{m m}>\pi_{B}^{d}$ is a necessary condition for a secure monopolist to have a greater incentive than an entrant to add the new product, because only the monopolist experiences a profit diversion on the old product.

\section{Product $A$ Is Initially Perfectly Competitive}

\footnotetext{
${ }^{14}$ This comparison yields $G^{m}-G^{d}=\left(\pi_{A}^{m m}+\pi_{B}^{m m}-\pi_{A}^{m}\right)-\pi_{B}^{d}$, whose sign is ambiguous. By contrast, the Introduction discussed Gilbert and Newbery's (1982) case where a monopolist faces a deterministic threat of entry and can acquire the innovation preemptively. The difference between its incentive and an entrant's is $G^{m p}-G^{d}=\left(\pi_{A}^{m m}+\pi_{B}^{m m}-\pi_{A}^{d}\right)-\pi_{B}^{d}$, since the incumbent's profit then drops from $\pi_{A}^{m}$ to $\pi_{A}^{d}$ if it fails to innovate. For this reason $G^{m p}-G^{d}$ can be signed, by rearranging it as $\left(\pi_{A}^{m m}+\pi_{B}^{m m}\right)-\left(\pi_{A}^{d}+\pi_{B}^{d}\right)>0$, the "efficiency effect" with a nondrastic product innovation.
} 
Instead of monopoly in $A$, suppose there are $n \geq 3$ symmetric and homogeneous Bertrand firms, each earning $\pi_{A}^{c}=0$. This corresponds to Arrow's (1962) competition case except that now the innovation brings a new product instead of a cost reduction on the old product. If any firm adds product $B$, the market structure will entail perfect competition in $A$ and monopoly in $B$. For brevity, we call this hybrid regime "Competition". The innovator's profit is denoted

$$
\pi_{B}^{c}=\max _{p_{B}}\left(p_{B}-c\right) D_{B}\left(c, p_{B}\right)<\pi_{B}^{d}
$$

The inequality in (6) holds because, with three or more firms in $A$, even if the innovator is one of them, the equilibrium price in $A$ will equal marginal cost $c .{ }^{15}$ This is lower than the price of $A$ when sold by a single firm, the initial monopolist. Thus, the gain to an innovator is larger under ex post duopoly than when $A$ is competitive:

$$
G^{d}=\pi_{B}^{d}>\pi_{B}^{c}=G^{c}
$$

Comparing the innovation incentive under competition $\left(G^{c}\right)$ to that under monopoly $\left(G^{m}\right)$ is relevant, for example, in the Merger scenario or Patent scenario discussed in the Introduction.

\section{Asymmetric Hotelling Framework}

To show that either the diversion effect or the coordination effect can dominate, we consider a Hotelling setting but letting the products differ not only in their locations but also in "quality".

\subsection{Ranking The Innovation Incentives}

Assume a unit mass of consumers, each having a unit demand and uniformly distributed on a Hotelling line $[0,1]$. When purchasing a unit of product $A$ or product $B$, a consumer at location $x$ receives net surplus $u_{A}=v_{A}-t x-p_{A}$ and $u_{B}=v_{B}-t(1-x)-p_{B}$, respectively, where $x \in[0,1]$, with good $A$ at $x=0$ and good $B$ at $x=1$. If $v_{A}=v_{B}$, the setting is the standard Hotelling model with pure horizontal product differentiation. Our formulation allows also quality differentiation: if $v_{B}>v_{A}$, then product $B^{\prime} s$ quality is higher, in the sense that an equidistant consumer values $B$ more than $A$, and conversely if $v_{B}<v_{A}$. We maintain the following assumption:

Assumption 1. 1.1) $\left.v_{A} \geq c+2 t, 1.2\right) v_{A}+v_{B}>2 c+3 t$, and 1.3) $\left|v_{B}-v_{A}\right|<2 t$.

\footnotetext{
${ }^{15}$ With just two firms in $A$, if one of them sells also $B$ then it will choose to abandon $A$ (unless the exit cost is substantial) so as to induce the rival to raise price (Judd, 1985).
} 
Assumption 1.1) implies that a monopolist over just good $A$ would cover the market and would set $\left.p_{A}=v_{A}-t ; 1.2\right)$ implies that the market would also be covered under duopoly; and 1.3) implies that when both products are present, each will have a positive output under either a two-good monopoly or under duopoly. ${ }^{16}$

If firm 1 is alone in the market and sells only product $A$, the optimal monopoly price and output are, respectively:

$$
p_{A}^{m}=v_{A}-t, \quad q_{A}^{m}=1
$$

and the monopoly profit is

$$
\pi_{A}^{m}=v_{A}-t-c
$$

Next, if firm 1 adds product $B$, it becomes a monopolist over both goods. For prices $p_{A}$ and $p_{B}$, the consumer who is indifferent between products $A$ and $B$ is located at $x_{i}$, given by $v_{A}-p_{A}-t x_{i}=v_{B}-p_{B}-t\left(1-x_{i}\right)$, or:

$$
x_{i}=\frac{t+v_{A}-v_{B}+p_{B}-p_{A}}{2 t}
$$

Thus, the demand functions are $q_{A}=x_{i}\left(p_{A}, p_{B}\right), q_{B}=1-x_{i}\left(p_{A}, p_{B}\right)$. Profit-maximization for the monopolist implies that the indifferent consumer will receive zero surplus: ${ }^{17}$

$$
v_{A}-p_{A}-t x_{i}=0
$$

Substituting for $x_{i}$ from (10) shows the relation between the highest prices that maintain market coverage:

$$
p_{B}=v_{A}-p_{A}-t+v_{B} .
$$

Since $\pi^{m m}=\left(p_{A}-c\right) x_{i}+\left(p_{B}-c\right)\left(1-x_{i}\right)$, where $x_{i}$ is given in (10) and $p_{A}$ and $p_{B}$ are related as shown in (11), we can express $\pi^{m m}$ as a function of only $p_{A}$. The first-order condition $d \pi^{m m} / d p_{A}=0$ here is sufficient for profit maximization and implies the following equilibrium prices and outputs for the two-product monopolist:

\footnotetext{
${ }^{16}$ Since $v_{A}$ is common to all consumers of good $A$, and similarly with $v_{B}$, what matters for profit functions and equilibrium values are the differences between quality and unit cost of the two products, $v_{A}-c_{A}$ and $v_{B}-c_{B}$. To simplify notation, we assume equal costs, $c_{A}=c_{B}=c$, and analyze differences in quality. All our ensuing results hold, however, if $c$ is set to 0 in the relevant expressions and $v_{A}$ and $v_{B}$ are interpreted net of costs. Thus, our results hold if the asymmetries are driven by cost, by quality, or some combination.

${ }^{17}$ Since all consumers purchase when only product $A$ is offered by the monopolist, it must be true that all consumers purchase when the monopolist offers both products.
} 


$$
\begin{array}{ll}
p_{A}^{m m}=\frac{3 v_{A}+v_{B}}{4}-\frac{t}{2}, & q_{A}^{m m}=\frac{1}{2}+\frac{v_{A}-v_{B}}{4 t} ; \\
p_{B}^{m m}=\frac{3 v_{B}+v_{A}}{4}-\frac{t}{2}, & q_{B}^{m m}=\frac{1}{2}+\frac{v_{B}-v_{A}}{4 t} .
\end{array}
$$

Compared to single-product monopoly, observe the following. When $v_{A}=v_{B}, q_{A}^{m m}=\frac{1}{2}$ and $p_{A}^{m m}=p_{A}^{m}+\frac{t}{2}$. Adding $B$ lets the firm cover the market at $p=v-\frac{t}{2}$, thus raising price by $\frac{t}{2}$ since the marginal consumer is now located at $x=\frac{1}{2}$ instead of $x=1$. If $v_{B}$ increases, the monopolist diverts sales to $B$ from $A\left(\Delta q_{B}=-\Delta q_{A}>0\right)$, while raising both prices. To see why the price of $A$ must rise, suppose that $p_{A}$ were held constant and $p_{B}$ were raised equally with $v_{B}$ to maintain zero surplus for the original indifferent consumer. Quantities would remain unchanged, but this allocation is no longer optimal: since only the margin on $B$ has risen, the monopolist gains by shifting sales from $A$ to $B$. To do so while holding the new indifferent consumer at zero surplus, it scales back the price increase on $B$ and raises the price of $A$ equally. (Thus, in equilibrium the quality-adjusted price of $B$ falls by $\Delta v_{B} / 4$ and $p_{A}$ rises by $\Delta v_{B} / 4$.)

The monopolist's profits from products $A$ and $B$ are:

$$
\begin{aligned}
& \pi_{A}^{m m}=\left(\frac{1}{4}\left(3 v_{A}+v_{B}-2 t\right)-c\right)\left(\frac{v_{A}-v_{B}+2 t}{4 t}\right), \\
& \pi_{B}^{m m}=\left(\frac{1}{4}\left(v_{A}+3 v_{B}-2 t\right)-c\right)\left(\frac{v_{B}-v_{A}+2 t}{4 t}\right) .
\end{aligned}
$$

Next, again with a monopolist in $A$, if a different firm adds $B$, the market becomes a duopoly. The profit functions are $\pi_{A}=\left(p_{A}-c\right) x_{i}\left(p_{A}, p_{B}\right), \pi_{B}=\left(p_{B}-c\right)\left(1-x_{i}\left(p_{A}, p_{B}\right)\right)$, where $x_{i}$ is given in (10) except that the relevant prices now are the duopoly prices $p_{A}^{d}, p_{B}^{d}$. These prices are determined by the first-order conditions:

$$
\begin{aligned}
\partial \pi_{A} / \partial p_{A} & =\frac{v_{A}-v_{B}+p_{B}-p_{A}+t}{2 t}-\left(p_{A}-c\right) \frac{1}{2 t}=0 \\
\partial \pi_{B} / \partial p_{B} & =\frac{-v_{A}+v_{B}-p_{B}+p_{A}+t}{2 t}-\left(p_{B}-c\right) \frac{1}{2 t}=0
\end{aligned}
$$

The duopoly equilibrium prices are

$$
p_{A}^{d}=c+t+\frac{v_{A}-v_{B}}{3}, \quad p_{B}^{d}=c+t+\frac{v_{B}-v_{A}}{3} .
$$

The corresponding equilibrium outputs are:

$$
q_{A}^{d}=x=\frac{1}{2}+\frac{v_{A}-v_{B}}{6 t}, \quad q_{B}^{d}=1-x=\frac{1}{2}+\frac{v_{B}-v_{A}}{6 t} .
$$

It can be easily verified that all consumers will have positive surplus and will thus indeed purchase 
given $v_{A}+v_{B}>2 c+3 t$ (Assumption 1.2).

Observe that if $v_{B}$ increases then $p_{A}$ falls under duopoly, whereas under joint monopoly $p_{A}$ rises (compare (16) and (12)). Moreover, as $v_{B}$ increases, the gap between $p_{B}$ and $p_{A}$ rises more slowly under monopoly than under duopoly: $\partial\left(p_{B}^{m m}-p_{A}^{m m}\right) / \partial v_{B}=1 / 2<2 / 3=$ $\partial\left(p_{B}^{d}-p_{A}^{d}\right) / \partial v_{B}$. Thus, $q_{B}$ increases faster at the expense of $q_{A}$ under monopoly than under duopoly since, using (10), $\partial q_{B} / \partial v_{B}=\left[1-\partial\left(p_{B}-p_{A}\right) / \partial v_{B}\right] / 2 t .{ }^{18}$ We summarize these observations in the following Remark.

Remark 3 Given the quality of the old good, $v_{A}$, an increase in the quality of the new good, $v_{B}$, will cause: (i) the price of $A$ to fall under duopoly but rise under monopoly; and (ii) the market share of $B$ to rise faster under monopoly.

Remark 3 illustrates sharply the coordination advantage in pricing of a two-product monopolist over an entrant that sells the new good $B$ and competes against a different seller of $A$.

From Remark 1, the incentive to add product $B$ is greater under monopoly than under duopoly $\left(G^{m}>G^{d}\right)$ if and only if $\left(\pi_{B}^{m m}-\pi_{B}^{d}\right)>\left(\pi_{A}^{m}-\pi_{A}^{m m}\right)$. Using (16) and (17), the equilibrium profit from product $B$ under duopoly is

$$
\pi_{B}^{d}=\frac{\left(3 t+v_{B}-v_{A}\right)^{2}}{18 t}
$$

Using the relevant profit expressions from (9), (13), (18) and performing some algebra yields:

$$
\left(\pi_{B}^{m m}-\pi_{B}^{d}\right)-\left(\pi_{A}^{m}-\pi_{A}^{m m}\right)=\frac{\left[12 t+5\left(v_{B}-v_{A}\right)\right]\left(v_{B}-v_{A}\right)}{72 t} .
$$

Assumption 1.3), $\left|v_{B}-v_{A}\right|<2 t$, implies $\left[12 t+5\left(v_{B}-v_{A}\right)\right]>0$. Thus,

$$
G^{m}-G^{d}=\left(\pi_{B}^{m m}-\pi_{B}^{d}\right)-\left(\pi_{A}^{m}-\pi_{A}^{m m}\right)>0 \Longleftrightarrow v_{B}>v_{A}
$$

When the innovator of $B$ instead faces perfect competition from good $A$ (instead of ex post duopoly), the equilibrium price and quantity of $B$ are

$$
p_{B}^{c}=c+\frac{v_{B}-v_{A}+t}{2}, \quad q_{B}^{c}=\frac{v_{B}-v_{A}+t}{4 t}
$$

\footnotetext{
${ }^{18}$ This discussion further implies that when $B$ is the stronger product, its market share will be larger under monopoly than under duopoly (and smaller when $B$ is weaker): using (10), $q_{B}-q_{A}=\left(v_{B}-v_{A}\right)-\left(p_{B}-p_{A}\right)$ and $\left(p_{B}-p_{A}\right)$ has the same sign as $\left(v_{B}-v_{A}\right)$ but is smaller in absolute value under monopoly. This market share discrepancy is relevant for our later discussion of drastic innovations.
} 
the equilibrium profit from $B$ is

$$
\pi_{B}^{c}=\left\{\begin{array}{ccc}
0 & \text { if } & t \leq v_{A}-v_{B} \\
\frac{\left(t-v_{A}+v_{B}\right)^{2}}{8 t} & \text { if } & v_{A}-v_{B}<t
\end{array},\right.
$$

and

$$
G^{m}-G^{c}=\left\{\begin{array}{cc}
\pi_{A}^{m m}+\pi_{B}^{m m}-\pi_{A}^{m}-\pi_{B}^{c}=G^{m}>0 & \text { if } t \leq v_{A}-v_{B} \\
\pi_{A}^{m m}+\pi_{B}^{m m}-\pi_{A}^{m}-\pi_{B}^{c}=\frac{3 t-2 v_{A}+2 v_{B}}{8}>0 & \text { if } \quad v_{A}-v_{B}<t
\end{array} .\right.
$$

We have thus established our main result:

Proposition 1 Assume that the products and consumer preferences are described by a Hotelling setting. (i) The incentive to add the new product $B$ is greater under Monopoly than under the Duopoly regime if and only if product $B$ has higher quality: $G^{m}>G^{d} \Longleftrightarrow v_{B}>v_{A}$. (ii) The incentive to add the new product $B$ is always greater under Monopoly than under Competition.

The monopoly versus duopoly ranking can be understood by starting with symmetry, $v_{A}=v_{B}$. If a monopolist over $A$ adds product $B$, it sets equal prices and continues serving the whole market, but raises price by $t / 2$, so its gain is $G^{m}=t / 2$. If, instead, an entrant adds product $B$, its price in the duopoly competition with the supplier of $A$ is $c+t$, so its margin is $t$, but it only captures $1 / 2$ the market. Its gain is $G^{d}=\pi_{B}^{d}=t / 2$, the same as for a monopolist.

Next, starting at $v_{A}=v_{B}$, consider increasing $v_{B}$ by a small amount $\delta$. From (12), a two-good monopolist would raise $p_{B}$ by $\delta 3 / 4$ and $p_{A}$ by $\delta / 4$. Since each good initially has half the sales and diversion from $A$ to $B$ is neutral when starting with equal margins, the first-order change in profit is just the average price increase, $\delta / 2$. Under duopoly, using (16) and (17), $p_{B}$ would only rise by $\delta / 3$ and only to $1 / 2$ the market, for a gain of $\delta / 6$; in addition, sales of $B$ expand by $\frac{\delta}{6 t}$ and the initial margin is $t$, so the first-order increase in profit is $\delta / 3$. Thus, an increase in the value of the new good $B$ raises profit by more when $B$ is added by the monopolist than by the entrant, showing that $G^{m}>G^{d}$ if and only if $v_{B}>v_{A}$ in the neighborhood of symmetric products. Straightforward algebra shows that, in fact, $\partial\left(\pi_{A}^{m m}+\pi_{B}^{m m}\right) / \partial v_{B}>\partial \pi_{B}^{d} / \partial v_{B}$ over the entire relevant range, hence $G^{m}=G^{d}$ at $v_{B}=v_{A}$ implies $G^{m}>G^{d}$ if and only if $v_{B}>v_{A}$.

\section{Drastic Product Innovations and Weak Nondrastic Product Innovations}

So far we have examined nondrastic product innovations - the old product continues to influence the innovator's equilibrium profit. In the Introduction, we noted that the innovation incentive is sure to be lower for a secure monopolist than for a firm initially earning zero profit if post innovation profit would be the same in either case - the unconstrained monopoly profit from the new product. This ex post equality requires the product innovation to be drastic starting from 
either market structure. The qualifier "either" is needed because, unlike a process innovation, a given product innovation can be drastic under one market structure but not another.

Specifically, in our Hotelling framework innovations are drastic for a broader range of parameter values under monopoly than when the innovator faces rivalry from the old good. ${ }^{19}$ The same pattern occurs in Greenstein and Ramey (1998) with vertical product differentiation. ${ }^{20}$ Intuitively, a separate firm would price the old product lower than would a joint monopolist because only a monopolist internalizes the profit diversion imposed on the new product. Thus, the old product maintains a constraining influence when available to a rival firm even in some cases where a joint monopolist would shut it down.

At the other end of the spectrum, consider a product innovation that is nondrastic and "weak" - a monopolist who sells both products will earn a much lower margin on the new than on the old. In the Hotelling framework, a weak new product can yield less profit to a joint monopolist than to an entrant, $\pi_{B}^{m m}<\pi_{B}^{d}$ (Remark 2). To see this possibility, observe that for $v_{B} \in\left(v_{A}-3 t, v_{A}-2 t\right)$ an entrant would add good $B$ while a monopolist over $A$ would not. (In (17), $v_{A}-3 t<v_{B}$ implies $q_{B}^{d}>0$; in (12), $v_{B}<v_{A}-2 t$ implies $q_{B}^{m m}=0$.) By continuity, an entrant's profit from $B$ exceeds a monopolist's also for some values $v_{B}>v_{A}-2 t$, when $B$ would be added under either regime (thereby satisfying Assumption 1.3). ${ }^{21}$ The logic is the same as for why some innovations are drastic under joint monopoly but not under rivalry. This time, the new product is the weaker one and a joint monopolist sets prices to divert sales to the stronger product more aggressively than would an entrant innovator selling only the weaker new product. (Recall the discussion before Remark 3.)

This discussion suggests an interesting non-monotonicity in the magnitude of innovations for

\footnotetext{
${ }^{19}$ Under monopoly, $q_{A}^{m m}=0$ if $v_{B} \geq v_{A}+2 t$, from (12); whereas under duopoly, $q_{A}^{d}>0$ as long as $v_{B}<v_{A}+3 t$, from (17) (the same condition maintains $q_{A}^{c}>0$, i.e., under the competition instead of duopoly regime). Moreover, even when the old product has no sales, under duopoly or competition it still constrains the price of the new good below the level that a joint monopolist would set. A joint monopolist that shuts down good $A$ and covers the market with $B$ will set $p_{B}^{m m}=v_{B}-t$, to yield zero surplus for the consumer located furthest from $B$. When $A$ is available to a competitor, in order to still cover the market the seller of $B$ must set its price under $v_{B}-t$, by an amount $v_{A}-c_{A}$, the surplus available to the consumer located furthest from $B$ if it bought $A$ at cost. Thus, in our Hotelling model a product innovation is never drastic under a rivalrous market structure, it can only be drastic under monopoly.

${ }^{20}$ See their Proposition 1. (As an aside, the innovation can be drastic under rivalrous market structures in their model, but this is not an inherent distinction between vertical and horizontal differentiation. It arises from their assumption that the market is not covered, so the marginal consumer that buys the old, low-quality good gets zero surplus. If, instead, the lowest type could get positive surplus from buying the old good at cost, then the availability of the old good to competitors would constrain the price of the new good even if sales of the old good were driven to zero.)

${ }^{21}$ For example, let $c=0, t=1$ and $v_{A}=2.5$. Then $\pi_{B}^{m m}<\pi_{B}^{d}$ if $v_{B} \in(0.5,1.1)$ and in this range the new product would be added under either monopoly or duopoly.
} 
which a monopolist's incentive to add the new product must be lower than an entrant's. This ranking occurs if the new product is sufficiently strong — a drastic innovation — or sufficiently weak. $^{22}$ The monopolist's incentive can be higher than an entrant's only in intermediate cases.

\subsection{Welfare Comparison}

\section{Total Welfare}

We have shown that when $v_{B}>v_{A}$, the incentive to introduce product $B$ is greater for a secure monopolist than for a would-be duopolist. Suppose now that adding product $B$ entails a fixed cost $f$. For certain values of $f$, product $B$ will be introduced under monopoly, but not otherwise. Can overall welfare, therefore, be higher under monopoly?

The answer is not immediate, since part of the monopolist's gain from adding the new product comes at the expense of consumers, as we show later. However, the following argument demonstrates that total welfare can be higher under monopoly.

Let $S$ denote consumer surplus and $W$ denote total welfare. If product $B$ is not introduced, the market is served fully with product $A$. If product $B$ is introduced by the monopolist, the change in total welfare is

$$
\Delta W=G^{m}-f+\Delta S
$$

since $G^{m}$ denotes the monopolist's gain before subtracting fixed costs. In order for the product to be introduced under monopoly but not under duopoly, $f$ must lie in the range

$$
G^{d}=\pi_{B}^{d} \leq f<\pi_{A}^{m m}+\pi_{B}^{m m}-\pi_{A}^{m}=G^{m}
$$

Suppose $\pi_{B}^{d}=f$. Then (21) becomes

$$
\Delta W=G^{m}-G^{d}+\Delta S
$$

\footnotetext{
${ }^{22}$ The reasoning, however, is different in the two cases. For a drastic innovation, post innovation profit is equal under both regimes, so it immediately follows that the monopolist's incentive to add the new product is lower because only it earns profit without the innovation. For a nondrastic innovation, this argument cannot be used since the monopolist's total post innovation profit is higher than an entrant's. However, the difference in incentives can be decomposed into the coordination effect on the new product and the diversion effect on the old (Remark 1). Since diversion arises only for the monopolist, a negative coordination effect, i.e., the monopolist earning less than an entrant on the new good alone, is sufficient to make the monopolist's incentive again lower than an entrant's. For intermediate innovations, the coordination effect will be positive and must be weighed against the diversion effect to determine the ranking of incentives.
} 
Recall that if $v_{B}>v_{A}$ then $G^{m}-G^{d}>0$. Furthermore, notice that

$$
G^{m}-G^{d}=\frac{\left[12 t+5\left(v_{B}-v_{A}\right)\right]\left(v_{B}-v_{A}\right)}{72 t}
$$

increases in $\left(v_{B}-v_{A}\right)$. As $\left(v_{B}-v_{A}\right)$ increases towards its limit of $2 t$ (Assumption 1.3)), good $B$ 's share of the market increases towards 1 and $A$ 's share falls towards 0 . Thus, consumer surplus under two-good monopoly becomes arbitrarily close to the level under single-good monopoly: Product $B$ instead of $A$ now serves (almost) all the market, and the monopolist fully appropriates the rise in product quality $v_{B}-v_{A}$ through an increase in price. The losing consumers are those who still buy $A$, but their mass can be made arbitrarily small. Therefore, as $v_{B}-v_{A}$ increases towards $2 t, \Delta S$ remains negative but becomes arbitrarily small, while $G^{m}-G^{d}$ is positive and increases, showing that in (23) $\Delta W>0$.

We therefore have:

Proposition 2 In the Hotelling setting, given the parameters $t$ and $c$, there exist parameter values $f, v_{A}, v_{B}$, with $v_{B}>v_{A}$, such that product $B$ is added under monopoly but not under duopoly and total welfare is higher under monopoly.

\section{Consumer Welfare}

In the above Hotelling setting, the introduction of the new product by the monopolist necessarily harms consumers. To see this, observe that with only product $A, p_{A}^{m}=v_{A}-t$ so the average consumer, located at $x=1 / 2$, earns surplus of $t / 2$. With both products offered, the indifferent consumer is located at $\hat{x}=\frac{v_{A}-v_{B}+p_{B}-p_{A}+t}{2 t} \in(0,1)$. The monopoly prices $\left(p_{A}^{m m}, p_{B}^{m m}\right)$ are set to leave this consumer zero surplus:

$$
v_{A}-p_{A}^{m m}-t \hat{x}=0=v_{B}-p_{B}^{m m}-t(1-\hat{x}) .
$$

Consumers located at $x<\hat{x}$ continue buying good $A$. The average such consumer is located at $\hat{x} / 2$ and earns surplus $t \hat{x} / 2$, less than the surplus $t / 2$ earned by the average consumer when only good $A$ was supplied. Consumers located at $x>\hat{x}$ switch to buying product $B$. The average such consumer is located at $(\hat{x}+1) / 2$ and therefore earns surplus

$$
v_{B}-p_{B}^{m m}-t[1-(1+\hat{x}) / 2]=t(1-\hat{x}) / 2
$$

When only product $A$ was available, that same consumer earned equal surplus:

$$
v_{A}-p_{A}^{m}-t(\hat{x}+1) / 2=t-t(\hat{x}+1) / 2=t(1-\hat{x}) / 2 .
$$


Thus, consumers that switched from product $A$ to $B$ in total earn the same surplus, while those who continue buying $A$ have lost.

The reduction of consumer welfare when the monopolist adds a new product, however, need not arise in other settings. In Appendix A, we present an extension of the Hotelling model where the monopolist's product innovation can benefit consumers. Thus, consumer welfare and overall welfare can both be higher under monopoly than under more rivalrous regimes, when the incentive to innovate is higher under monopoly.

\section{$5 \quad$ Horizontal versus Vertical Product Differentiation}

Instead of our Hotelling framework, Greenstein and Ramey (1998, "GR") analyze vertical product differentiation (Shaked and Sutton, 1983; Tirole, 1988). Also, under duopoly they assume Cournot competition while we assume Bertrand. To isolate the role of the demand systems we compare the ranking of incentives in the two models for common regimes: monopoly in both goods $(\mathrm{mm})$ versus competition in the old good and monopoly in the new (regime $c$, GR's "dominant-fringe structure"). In our model, the incentive to add the new product is greater under monopoly than under competition (Proposition 1) and the incentive gap grows with the advantage of the new product. GR find that for any innovation that is non-drastic under both regimes, the incentives under monopoly or competition are equal, $G^{m}=G^{c}$ (Proposition 2(a)). ${ }^{23}$

Why is vertical differentiation less favorable than horizontal differentiation for a monopolist's incentive to add a product? To trace the fundamental difference we first review the intuition for GR's results and then briefly revisit the Hotelling framework.

\subsection{Vertical Differentiation}

Greenstein and Ramey consider a continuum of consumers whose type $\omega$ indicates their willingness to pay. Each consumer demands at most one unit of either the old or new good, and the gross surplus from buying is $f_{O}(\omega)$ or $v f_{N}(\omega)$. The parameter $v>0$ indexes the innovation's magnitude. All types value the new good more than the old, $v f_{N}(\omega)>f_{O}(\omega)$ for all relevant $v$; gross surplus from either good increases with type, as does the premium offered for the new good: $v f_{N}^{\prime}(\omega)>0, f_{O}^{\prime}(\omega)>0$, and $v f_{N}^{\prime}(\omega)>f_{O}^{\prime}(\omega)$. At prices $p_{N}>p_{O}$ such that both goods

\footnotetext{
${ }^{23}$ We shall use our notation to denote the various regimes also when discussing their paper. For the reader's convenience, we recap here the names of our regimes, and note in parentheses their counterparts in GR: monopoly over only the old good, indexed by superscript " $m$ " (Old Monopoly, OM); Monopoly over both goods, " $m m$ " (Joint Monopoly, M); Competition in the old good and monopoly in the new, "c" (Dominant-Fringe Structure, C); Duopoly ex post, with a different supplier of each good, "d" (D).
} 
have positive sales there are two marginal types of consumers. Type $\omega_{O}$ is indifferent between buying the old good or none: $f_{O}\left(\omega_{O}\right)-p_{O}=0$. Type $\omega_{N}>\omega_{O}$ is indifferent between the two goods: $f_{O}\left(\omega_{N}\right)-p_{O}=v f_{N}\left(\omega_{N}\right)-p_{N}$. Consumer types between $\omega_{O}$ and $\omega_{N}$ buy the old good, generating sales $q_{O}$; those above $\omega_{N}$ buy the new good, generating sales $q_{N}{ }^{24}$

Facts F1-F3 below help understand the equilibrium choices of a two-good monopolist whenever both goods are sold (i.e., when $\omega_{N}>\omega_{O}$, so the innovation is nondrastic). F1: Total quantity sold $\left(q=q_{O}+q_{N}\right)$ depends only on the price of the low quality good since $p_{O}$ alone determines the identity of type $\omega_{O}$ (equivalently, $p_{O}$ depends only on total quantity $q$ ). F2: An equal increase in both prices that leaves $q_{O}>0$ does not affect sales of the new good, $q_{N}$ : since $\omega_{N}$ is unchanged and this consumer retains positive surplus $\left(\omega_{N}>\omega_{O} \Longrightarrow f_{O}\left(\omega_{N}\right)-p_{O}>f\left(\omega_{O}\right)-p_{O}=0\right)$, all types $\omega \geq \omega_{N}$ will continue to buy the new good. F3: Rearranging the condition determining $\omega_{N}$ as $p_{N}-p_{O}=v f_{N}\left(\omega_{N}\right)-f_{O}\left(\omega_{N}\right)$ shows that the price premium that can be collected for the new good is independent of the quantity of the old - it depends only on the identity of type $\omega_{N}$ and, hence, only on the quantity of the new good $q_{N}$.

GR's Proposition 2(a) flows directly from their Lemma, which establishes two properties: (a) the total quantity sold by a two-good monopolist equals that sold by a monopolist over only the old good, $q_{O}^{m m}+q_{N}^{m m}=q_{O}^{m}$; and (b) the quantity of the new good sold by a two-good monopolist equals that sold by a monopolist that faces perfect competition from the old good, $q_{N}^{m m}=q_{N}^{c}$. We now explain the intuition for these results and their implication.

Start with part (a). For a two-good monopolist, profit is $\pi^{m m}=\left(p_{O}-c_{O}\right) q_{O}+\left(p_{N}-c_{N}\right) q_{N}$. Using $q=q_{O}+q_{N}$ profit can be decomposed as $\left(p_{O}-c_{O}\right) q+\left[p_{N}-p_{O}-\left(c_{N}-c_{O}\right)\right] q_{N}$ : the profit that would be earned if a total quantity $q$ of the low-quality good were sold at its price $p_{O}$ plus the premium earned by actually diverting the quantity $q_{N}$ from the old good to the new. Term $\left(p_{O}-c_{O}\right) q$ depends only on total quantity $q$ (since $p_{O}$ depends only on $q$, by F1), while the other term depends only on $q_{N}$ (since the premium $p_{N}-p_{O}$ depends only on $q_{N}$, by F3), so the optimal choice of $q$ is separable from that of $q_{N}$ (i.e., of the optimal mix between the two goods). A monopolist that only sold the old good would choose $q$ to maximize expression $\left(p_{O}-c_{O}\right) q$. Therefore, the total quantity chosen will be the same in both cases: $q^{m m}=q_{O}^{m} \cdot{ }^{25}$ Since total quantity depends only on the price of that low-quality good, its price also must remain unchanged,

\footnotetext{
${ }^{24} \mathrm{GR}$ make the usual simplifying assumptions, that $\omega$ is uniformly distributed on [0,1] and the mass of consumers is one, but these are not essential for the ensuing results. With those assumptions, the quantities are $q_{N}=1-\omega_{N}$, $q_{O}=\omega_{N}-\omega_{O}$.

${ }^{25}$ The following provides additional intuition. The output $q_{O}^{m}$ satisfies the standard marginal condition: the loss from a small output reduction, $\left(p_{O}^{m}-c_{O}\right)$, equals the resulting price increase $f_{O}^{\prime}\left(\omega_{O}^{m}\right)$ multiplied by the remaining output $q_{O}^{m}$. A two-good monopolist faces an identical tradeoff when reducing total quantity: it loses the margin on the old good, $p_{O}-c_{O}$, but raises price by $f_{O}^{\prime}\left(\omega_{O}\right)$ on both the old good's quantity $q_{O}$ and on $q_{N}$, because whatever the level of $q_{N}$, it remains constant if both prices are raised equally (by F2). Therefore $q^{m m}=q_{O}^{m}$.
} 
$p_{O}^{m m}=p_{O}^{m} \cdot{ }^{26}$ Thus, by the earlier decomposition, the profit of a two-good monopolist equals the profit earned by a monopolist that sold only the old good, $\left(p_{O}^{m m}-c_{O}\right) q_{O}^{m}$, plus the premium from adding the new good, discussed next.

Now consider part (b), why $q_{N}^{m m}=q_{N}^{c}$. The condition determining $\omega_{N}$, hence $q_{N}$, yields the inverse demand function $P_{N}\left(q_{N} \mid p_{O}\right)=v f_{N}\left(\omega_{N}\right)-\left(f_{O}\left(\omega_{N}\right)-p_{O}\right)$ : the price that can be charged for the new good for a given quantity equals the gross surplus to the corresponding type $\omega_{N}$ from the new good minus the net surplus it can get by buying the old good. Note that $P_{N}\left(q_{N} \mid p_{O}^{m m}\right)=$ $P_{N}\left(q_{N} \mid c_{O}\right)+\left(p_{O}^{m m}-c_{O}\right)$. When a monopolist over the new good faces perfect competition from the old $\left(p_{O}=c_{O}\right)$ it chooses $q_{N}$ to maximize the profit function $\left[P_{N}\left(q_{N} \mid c_{O}\right)-c_{N}\right] q_{N}$. Denote the equilibrium quantity, price, and profit by $q_{N}^{c}, p_{N}^{c}=P_{N}\left(q_{N} \mid c_{O}\right)$, and $\pi_{N}^{c}=\left(p_{N}^{c}-c_{N}\right) q_{N}^{c}$. With a two-good monopolist, we saw that $q_{N}$ is chosen to maximize the "premium" term $\left[p_{N}-\right.$ $\left.p_{O}^{m m}-\left(c_{N}-c_{O}\right)\right] q_{N}$ or $\left[P_{N}\left(q_{N} \mid p_{O}^{m m}\right)-\left(p_{O}^{m m}-c_{O}\right)-c_{N}\right] q_{N}$, which is the same as $\left[P_{N}\left(q_{N} \mid c_{O}\right)-\right.$ $\left.c_{N}\right] q_{N}$, the profit function of a monopolist over the new good that faces competition from the old. Therefore, the optimal $q_{N}$ must be identical in both cases, $q_{N}^{m m}=q_{N}^{c} \cdot{ }^{27}$ The extra profit (premium term) to an initial monopolist from adding the new good therefore also equals $\pi_{N}^{c}=$ $\left(p_{N}^{c}-c_{N}\right) q_{N}^{c}$.

Using both parts of the Lemma, the profit of a two-good monopolist is $\pi^{m m}=\pi_{O}^{m}+\pi_{N}^{c}$. The gain from adding the new good therefore is the same under either regime: $G^{m}=\pi^{m m}-\pi_{O}^{m}=$ $\pi_{N}^{c}=G^{c}$. By contrast, in the asymmetric Hotelling model our Proposition 1 showed that the gain from adding the new product is greater under monopoly than under competition (and also greater than under duopoly if the new product's quality is higher, $v_{B}>v_{A}$ ).

\subsection{Comparing Vertical and Horizontal Differentiation}

The key difference between vertical and horizontal differentiation is the identity of the marginal types of consumers and what this implies for pricing by a two-product monopolist. ${ }^{28}$ With vertical differentiation, there are two marginal types: type $\omega_{N}$ who is indifferent between the two goods and gets positive surplus; and a lower type $\omega_{O}$ who is indifferent between the low-quality old good

\footnotetext{
${ }^{26}$ In the Hotelling model, when the monopolist adds a new good recall that total quantity also stays unchanged but the price of the old good rises, a point we shall revisit.

${ }^{27}$ Intuitively, when moving from regime " $c$ " (competition in the old good and monopoly in the new) to regime " $m m$ " (joint monopoly), two effects on the marginal profitability of expanding $q_{N}$ exactly cancel: (i) the price of the old good rises by $p_{O}^{m m}-c_{O}$, as does the price of the new good for any $q_{N}$, so the per-unit gain from expanding $q_{N}$ increases by $p_{O}^{m m}-c_{O}$; but (ii) each unit of the new good diverts one unit of the old, which reduces profit of the two-good monopolist by $p_{O}^{m m}-c_{O}$. Thus, the optimal quantity of the new good stays $q_{N}^{c}$.

${ }^{28}$ In both settings, when a monopolist adds the new product total quantity stays unchanged, so this is not the source of divergence.
} 
and not buying at all, hence gets zero surplus. The consumers who choose the new good are the relatively higher types, not those who are on the margin of buying the old good versus dropping out. This structure implies a division of labor between a monopolist's two prices: the price of the low-quality good is set to determine total sales, and the price of the new good determines the mix of sales. Under horizontal differentiation, the consumers attracted to the new good are those who get relatively low surplus from the old. This permits a joint monopolist more latitude in raising the price of the old good to divert sales to the new without causing some consumers to drop out of the market.

To illustrate the differential pricing latitude we analyze for the Hotelling model the same comparisons as in parts a) and b) of GR's Lemma. First consider the price adjustments when a monopolist over the old good adds the new good (moving from regime $m$ to $m m$ - part a) of GR's Lemma). Under vertical differentiation, the price of the old, low-quality good remains unchanged to avoid reducing total sales. Under horizontal differentiation, adding the new product $B$ lets the monopolist raise the price of $A$ while maintaining market coverage. When only good $A$ is offered, its price is set to yield zero surplus for the consumer located furthest away — which is where $\operatorname{good} B$ is added. Thus, the previously marginal consumer and consumers close to it will switch to the new good. The new consumer who is indifferent between the two goods will be less distant from $A$ than was the original marginal consumer of $A$ and, hence, would enjoy positive surplus if the price of $A$ were unchanged after $\operatorname{good} B$ is added. The monopolist therefore raises the price of the old good without losing aggregate sales: all consumers who stop buying the old good will divert to the new good. ${ }^{29}$

Next, consider a monopolist over the new good acquiring control of the initially competitive old good (moving from regime $c$ to $m m$ - part b) of GR's Lemma). With vertical differentiation, sales of the new good stay unchanged because prices of both goods are raised equally. Under horizontal differentiation, sales of the new good will increase $\left(q_{B}^{m m}>q_{B}^{c}\right)$ because the monopolist will raise price by more for the old good than for the new. To see why, start with the equilibrium quantities when $B$ is monopolized but $A$ is competitive, and consider raising both prices equally until the indifferent consumer $\left(x_{i}\right)$ gets zero surplus, thus maintaining market coverage and the initial quantities of both goods. At this price profile, good $B$ remains under-supplied relative to $A$ from the standpoint of the joint monopolist's profit, since the ratio $q_{B}^{c} / q_{A}^{c}$ emerged when the monopolist controlled only the price of $B$. A joint monopolist therefore will shift sales from $A$ to $B$ by raising the price of $A$ and cutting the price of $B$ equally (keeping the indifferent consumer

\footnotetext{
${ }^{29}$ And as the quality of the new good $v^{B}$ rises, the monopolist raises the price also of the old good while maintaining market coverage. Under vertical differentiation, the price of the low-quality good remains unchanged as the quality of the new one, $v$, increases so long as the old good still retains any positive sales.
} 
at zero surplus) without losing aggregate sales. ${ }^{30}$ By contrast, under vertical differentiation a rise in the price of the old, low-quality good matched by an equal cut in the price of the new good would reduce total sales - because the old good competes at two margins: with the new one and with outside goods.

The above models involve discrete choices by heterogeneous consumers. We have also analyzed the familiar model of a representative consumer with quadratic utility function over, and elastic demands for, the two differentiated products (see Appendix B). Interestingly, the ranking of incentives to add the new product is the same as in GR, $G^{m}=G^{c}<G^{d}$. Despite the different preference structures and resulting demand systems, the representative consumer case shares two features with vertical - but not horizontal - differentiation. When a monopolist over the old good adds the new product, (i) an increase in the price of the old good would reduce total sales, and in equilibrium that price is left unchanged; and (ii) sales of the new good under joint monopoly are the same as in the case where the old good is competitive.

This discussion suggests the following principle. When comparing the incentive of a monopolist to add a second product relative to the incentive of a more rivalrous firm, a key factor is the extent to which the monopolist can divert sales to the new product as opposed to leaking sales to outside goods if it raises the price of its old product.

\section{Conclusion}

In contrast to Arrow's pioneering analysis of a process innovation, this paper showed in a Hotelling framework that the incentive to invest in a nondrastic product innovation can be higher under a secure monopoly than under market structures that feature product market rivalry.

Compared to a firm that earns lower profit initially (e.g., an entrant or a Bertrand competitor) and will face rivalry from independent sellers of the old product post innovation, the monopolist's incentive can be decomposed into two opposing effects. The monopolist loses more profit on the old product (diversion effect) but may earn more profit on the new one (coordination effect) because it prices the old product in a way that internalizes the effect on the new one.

The relative strength of these opposing diversion and coordination effects depends on the particular properties of demand. Collectively, our findings and the results of Greenstein and

\footnotetext{
${ }^{30} \mathrm{~A}$ small cut in the price of $B$ alone would leave profit unchanged, because $q_{B}^{c}$ was the monopolist's interior optimum choice when it only controlled $B$, and the tradeoff from cutting the price of $B$ remains unchanged if the monopolist acquires $A$ and raises both prices equally. (The margin on $B$ has risen, but the opportunity cost of selling $B$ has risen equally since the monopolist now internalizes diversion from $A$, the same logic as in part b of GR's Lemma.) However, a price reduction on $B$ permits an increase in the price of $A$ while maintaining market coverage, and this combination of price changes will raise profit.
} 
Ramey (1998) suggest that the ranking of incentives to invest in product innovations across market structures will be quite sensitive to the nature of product differentiation. 


\section{Appendix A: Extended Hotelling Model}

We extend the Hotelling model in Section 3 so that the producer of the new product $(B)$ will have monopoly power on an additional segment of consumers. Specifically, in addition to the unit mass of consumers on the Hotelling line, we assume that there is also a mass of $\alpha \geq 0$ consumers who only like the new product $B$, each having a unit demand and valuing product $B$ at $v$, where $v$ is the realization of a random variable with $\operatorname{cdf} F(v)$ on support $[\underline{v}, \bar{v}] .{ }^{31}$ Notice that if $\alpha=0$, the model reduces to the Hotelling model. We assume that the producer of $B$ is able to charge a separate price to the $\alpha$ consumers.

Let

$$
p_{\alpha}^{m}=\arg \max _{p_{\alpha}}\left(p_{\alpha}-c\right)\left[1-F\left(p_{\alpha}\right)\right]
$$

and

$$
\pi_{\alpha}^{m}=\alpha\left(p_{\alpha}^{m}-c\right)\left[1-F\left(p_{\alpha}^{m}\right)\right]
$$

For convenience, we assume:

Assumption 2. $p_{\alpha}^{m} \in(c, \bar{v})$ exists, and $\int_{p_{\alpha}^{m}}^{\bar{v}}[1-F(p)] d p \geq \frac{t}{4}$.

Since the price to the $\alpha$ consumers is set separately, the presence of these consumers will increase the profit from product $B$ by $\pi_{\alpha}^{m}$, regardless of which firm adds (innovates) $B$, and will not affect the profits from the Hotelling line. Thus, the profit from product $A$ by a single product monopolist is still $\pi_{A}^{m}$, the profits from $A$ and $B$ under duopoly are now $\pi_{A}^{d}$ and $\Pi_{B}^{d}=\pi_{B}^{d}+\pi_{\alpha}^{m}$, and the profits from $A$ and $B$ under multiproduct monopoly are $\pi_{A}^{m m}$ and $\Pi_{B}^{m m}=\pi_{B}^{m m}+\pi_{\alpha}^{m}$. Since the gains from innovation are now $\hat{G}^{m}=G^{m}+\pi_{\alpha}^{m}$ and $\hat{G}^{d}=G^{d}+\pi_{\alpha}^{m}$, we again have $\hat{G}^{m}>\hat{G}^{d}$ if and only if $v_{B}>v_{A}$.

While the presence of $\alpha$ consumers has no effect on the comparison of innovation incentives, it increases the consumer surplus brought about by product $B$.

When only product $A$ is sold, consumer surplus is:

$$
S_{A}^{m}=\int_{0}^{1}\left(v_{A}-\left(v_{A}-t\right)-t x\right) d x=\frac{t}{2} .
$$

\footnotetext{
${ }^{31}$ We could alternatively assume that the $\alpha$ consumers each have a downward sloping demand $\alpha D(p)$.
} 
When both product $A$ and product $B$ are sold by firm 1, consumer surplus is:

$$
\begin{aligned}
S^{m m}= & \int_{0}^{\frac{2 t+v_{A}-v_{B}}{4 t}}\left(v_{A}-\frac{1}{4}\left(3 v_{A}-2 t+v_{B}\right)-t x\right) d x+ \\
& \int_{\frac{2 t+v_{A}-v_{B}}{4 t}}^{1}\left(v_{B}-\frac{1}{4}\left(v_{A}-2 t+3 v_{B}\right)-t(1-x)\right) d x+\alpha \int_{p_{\alpha}^{m}}^{\bar{v}}[1-F(p)] d p \\
= & \frac{\left(v_{B}-v_{A}-2 t\right)^{2}}{32 t}+\frac{\left(2 t-v_{A}+v_{B}\right)^{2}}{32 t}+\alpha \int_{p_{\alpha}^{m}}^{\bar{v}}[1-F(p)] d p \\
= & \frac{4 t^{2}+\left(v_{B}-v_{A}\right)^{2}}{16 t}+\alpha \int_{p_{\alpha}^{m}}^{\bar{v}}[1-F(p)] d p .
\end{aligned}
$$

We thus have:

$$
\begin{aligned}
S^{m m}-S^{m} & =\frac{4 t^{2}+\left(v_{B}-v_{A}\right)^{2}}{16 t}-\frac{t}{2}+\alpha \int_{p_{\alpha}^{m}}^{\bar{v}}[1-F(p)] d p \\
& =\frac{\left(v_{B}-v_{A}\right)^{2}-(2 t)^{2}}{16 t}+\alpha \int_{p_{\alpha}^{m}}^{\bar{v}}[1-F(p)] d p .
\end{aligned}
$$

Note that for $\alpha=0$, since $\left|v_{B}-v_{A}\right|<2 t$ from Assumption 1.3), $S^{m m}-S^{m}<0$, showing that consumer surplus in our original Hotelling model falls when a monopolist adds the second product. However, $S^{m m}-S^{m}$ increases in $\alpha$, and, $S^{m m}-S^{m}>0$ if $\alpha=1$. Therefore:

Proposition 3 Assume $v_{B}>v_{A}$ and the fixed cost to innovate product $B$ is

$$
f \in\left(\Pi_{B}^{d}, \pi_{A}^{m m}+\Pi_{B}^{m m}-\pi_{A}^{m}\right)
$$

Then there exists some $\hat{\alpha} \in(0,1)$ such that aggregate consumer surplus is higher (lower) under Monopoly than under the Duopoly regime if $\alpha>\hat{\alpha}(\alpha<\hat{\alpha})$.

Thus consumer welfare can be higher under monopoly due to the product innovation that would not be profitable if the innovator had to face price competition from the old good. 


\section{Appendix B: Representative Consumer with Quadratic Utility}

Assume that the inverse demand system is given by :

$$
p_{A}=1-q_{A}-\gamma q_{B}, \quad p_{B}=a-b q_{B}-\gamma q_{A},
$$

where $a$ denotes the demand advantage of the new good, and we assume $a \geq \gamma>0$, and $b>a \gamma$ so that a multiproduct monopolist would produce positive quantities for both products. This demand system can be generated by a representative consumer with the familiar quasi-linear utility function, that is additive in income and in a quadratic sub-utility function defined over the differentiated goods (Vives 1999):

$$
U\left(q_{A}, q_{B}\right)=q_{A}+a q_{B}-\frac{1}{2}\left(q_{A}^{2}+2 \gamma q_{A} q_{B}+b q_{B}^{2}\right) .
$$

We normalize constant marginal cost $c=0$. The direct demand system is

$$
q_{A}=\frac{b-a \gamma-b p_{A}+\gamma p_{B}}{b-\gamma^{2}}, \quad q_{B}=\frac{a-\gamma-p_{B}+\gamma p_{A}}{b-\gamma^{2}} .
$$

First, for a monopolist producing only product $A$, the demand for $A$ is

$$
D^{m}\left(p_{A}\right)=1-p_{A} .
$$

The monopoly price, output, and profit are, respectively,

$$
p_{A}^{m}=\frac{1}{2} ; \quad q_{A}^{m}=\frac{1}{2} ; \quad \pi_{A}^{m}=\frac{1}{4} .
$$

Next, if firm 1 innovates $B$, it becomes a monopolist in both $A$ and $B$. It thus chooses $p_{A}$ and $p_{B}$ to maximize

$$
p_{A} \frac{b-a \gamma-b p_{A}+\gamma p_{B}}{b-\gamma^{2}}+p_{B} \frac{a-\gamma-p_{B}+\gamma p_{A}}{b-\gamma^{2}} .
$$

We obtain:

$$
\begin{aligned}
& p_{A}^{m m}=\frac{1}{2}, \quad p_{B}^{m m}=\frac{a}{2} ; \quad q_{A}^{m m}=\frac{b-\gamma a}{2\left(b-\gamma^{2}\right)}, \quad q_{B}^{m m}=\frac{a-\gamma}{2\left(b-\gamma^{2}\right)} \\
& \pi_{A}^{m m}=\frac{b-\gamma a}{4\left(b-\gamma^{2}\right)}, \quad \pi_{B}^{m m}=\frac{a^{2}-\gamma a}{4\left(b-\gamma^{2}\right)} .
\end{aligned}
$$

Next, if the competitor innovates $B$, the market becomes a duopoly. The profits of firms $A$ and 
$B$, respectively, are

$$
p_{A} \frac{b-a \gamma-b p_{A}+\gamma p_{B}}{b-\gamma^{2}}, \quad p_{B} \frac{a-\gamma-p_{B}+\gamma p_{A}}{b-\gamma^{2}} .
$$

We obtain the equilibrium prices and outputs as

$$
\begin{aligned}
p_{A}^{d} & =\frac{2 b-a \gamma-\gamma^{2}}{4 b-\gamma^{2}}, \quad p_{B}^{d}=\frac{2 a b-b \gamma-a \gamma^{2}}{4 b-\gamma^{2}} \\
q_{A}^{d} & =\frac{\left(2 b-a \gamma-\gamma^{2}\right) b}{\left(4 b-\gamma^{2}\right)\left(b-\gamma^{2}\right)}, \quad q_{B}^{d}=\frac{\left(2 a b-b \gamma-a \gamma^{2}\right)}{\left(4 b-\gamma^{2}\right)\left(b-\gamma^{2}\right)}
\end{aligned}
$$

The equilibrium profits are:

$$
\pi_{A}^{d}=\frac{\left(2 b-a \gamma-\gamma^{2}\right)^{2} b}{\left(4 b-\gamma^{2}\right)^{2}\left(b-\gamma^{2}\right)}, \quad \pi_{B}^{d}=\frac{\left(2 a b-b \gamma-a \gamma^{2}\right)^{2}}{\left(4 b-\gamma^{2}\right)^{2}\left(b-\gamma^{2}\right)} .
$$

Finally, if the production of $A$ is competitive, then $p_{A}^{c}=M C=0$, and

$$
q_{B}=\frac{a-\gamma-p_{B}+\gamma p_{A}}{b-\gamma^{2}}=\frac{a-\gamma-p_{B}}{b-\gamma^{2}} .
$$

Maximizing $\pi_{B}=p_{B} q_{B}$, we obtain:

$$
p_{B}^{c}=\frac{a-\gamma}{2}, \quad q_{B}^{c}=\frac{a-\gamma}{2\left(b-\gamma^{2}\right)}, \quad \pi_{B}^{c}=\frac{(a-\gamma)^{2}}{4\left(b-\gamma^{2}\right)} .
$$

Straightforward calculations reveal

$$
\begin{aligned}
G^{m}-G^{d} & =\left(\pi_{B}^{m m}-\pi_{B}^{d}\right)-\left(\pi_{A}^{m}-\pi_{A}^{m m}\right) \\
& =\frac{\left(2 b-a \gamma-\gamma^{2}\right)\left(6 b \gamma-8 a b-\gamma^{3}+3 a \gamma^{2}\right) \gamma}{4\left(4 b-\gamma^{2}\right)^{2}\left(b-\gamma^{2}\right)} .
\end{aligned}
$$

Since $a \geq \gamma$ and $b>a \gamma \geq \gamma^{2}$ by assumption, we have

$$
2 b-a \gamma-\gamma^{2}=b-a \gamma+b-\gamma^{2}>0,
$$

and

$$
6 b \gamma-8 a b-\gamma^{3}+3 a \gamma^{2}=b(6 \gamma-8 a)+\gamma^{2}(3 a-\gamma)<0,
$$


and hence $G^{m}-G^{d}<0$. On the other hand,

$$
G^{m}-G^{c}=\left(\pi_{B}^{m m}-\pi_{B}^{c}\right)-\left(\pi_{A}^{m}-\pi_{A}^{m m}\right)=\frac{a^{2}-\gamma a}{4\left(b-\gamma^{2}\right)}-\frac{(a-\gamma)^{2}}{4\left(b-\gamma^{2}\right)}-\left(\frac{1}{4}-\frac{b-\gamma a}{4\left(b-\gamma^{2}\right)}\right)=0
$$

We have thus established:

Proposition 4 If the demand system is given by (24), then $G^{d}>G^{m}=G^{c}$. 


\section{References}

Arrow, K. (1962). "Economic Welfare and the Allocation of Resources for Innovations," R. Nelson ed. The Rate and Direction of Inventive Activity, Princeton University Press.

Chen, Y. (2000). "Strategic Bidding by Potential Competitors: Will Monopoly Persist." Journal of Industrial Economics, 48: 161-175.

Eaton, B.C. and Lipsey, R.G. (1979). "The Theory of Market Pre-emption: The Persistence of Excess Capacity and Monopoly in Growing Spatial Markets," Economica, 46: 149-158.

Gallini, N. and Winter, R. (1985). "Licensing in the Theory of Innovation," Rand Journal of Economics, 16: $237-252$.

Gans, J. and S. Stern (2000). "Incumbency and R\&D Incentives: Licensing the Gale of Creative Destruction," Journal of Economics \&3 Management Strategy, 9: 485-511.

Gilbert, R. (2006). "Looking for Mr. Schumpeter: Where Are We in the Competition-Innovation Debate?" in Innovation Policy and the Economy, A. Jaffe, J. Lerner, and S. Stern eds., National Bureau of Economic Research.

Gilbert, R. and Newbery, D. (1982). "Preemptive Patenting and the Persistence of Monopoly," American Economic Review, 72: 514-526.

Gilbert, R. and Newbery, D. (1984). "Preemptive Patenting and the Persistence of Monopoly: Reply," American Economic Review, 74: 251-253.

Greenstein, S. and Ramey, G. (1998). "Market Structure, Innovation, and Vertical Product Differentiation," International Journal of Industrial Organization, 16: 285-311.

Hotelling, H. (1929). "Stability in Competition," Economic Journal, 39: 41-57.

Judd, K. (1985). "Credible Spatial Preemption," Rand Journal of Economics, 16: 153-166.

Katz, M. and Shapiro, C. (1987). "R\&D Rivalry with Licensing or Imitation," American Economic Review, 77: 402-420.

Lewis, T. (1983). "Preemption, Divestiture, and Forward Contracting in a Market Dominated by a Single Firm," American Economic Review, 73: 1092-1101.

Malueg, D.A. and Schwartz, M. (1991). "Preemptive Investment, Toehold Entry, and the Mimicking Principle," Rand Journal of Economics, 22: 231-246.

Reinganum, J.F. (1983). "Uncertain Innovation and the Persistence of Monopoly," American Economic Review, 73: 741-748.

Reinganum, J.F. (1989). "The Timing of Innovation: Research, Development, and Diffusion," Handbook of Industrial Organization, Vol. 1, R. Schmalensee and R.D. Willig eds.

Salant, S. (1984). "Preemptive Patenting and the Persistence of Monopoly: Comment," American Economic Review, 74: 247-250.

Shaked, A. and Sutton, J. "Natural Oligopolies," Econometrica, 51: 1469-1483.

Spulber, D (2009). "Product Differentiation and Strategic Innovation: Entrepreneurship versus Technology Transfer," Auguest, Northwestern University working paper.

Tirole, J. (1988). The Theory of Industrial Organization, MIT Press.

Vives, X. (1999). Oligopoly Pricing: Old Ideas and New Tools, MIT Press. 